\title{
Sleep Disturbance in Cancer Patients Referred to an Ambulatory Integrative Oncology Consultation
}

\section{Santhosshi Narayanan ( $\nabla$ snarayanan2@mdanderson.org )}

The University of Texas MD Anderson Cancer Center Division of Cancer Medicine https://orcid.org/0000-0003-0591-1500

\section{Akhila Reddy}

The University of Texas MD Anderson Cancer Center Division of Cancer Medicine

\section{Gabriel Lopez}

The University of Texas MD Anderson Cancer Center

\section{Wenli Liu}

The University of Texas MD Anderson Cancer Center

\section{Sara Ali}

The University of Texas MD Anderson Cancer Center

\section{Eduardo Bruera}

The University of Texas MD Anderson Cancer Center

\section{Lorenzo Cohen}

The University of Texas MD Anderson Cancer Center

\section{Sriram Yennurajalingam}

The University of Texas MD Anderson Cancer Center

\section{Research Article}

Keywords: Insomnia, Integrative Oncology, Complementary Medicine, Sleep Disturbance, Patient Reported Outcomes

Posted Date: July 30th, 2021

DOl: https://doi.org/10.21203/rs.3.rs-662550/v1

License: (c) (1) This work is licensed under a Creative Commons Attribution 4.0 International License. Read Full License

Version of Record: A version of this preprint was published at Supportive Care in Cancer on November 11th, 2021. See the published version at https://doi.org/10.1007/s00520-021-06668-x. 


\section{Abstract \\ Background}

Sleep disturbance (SD) is highly prevalent in oncology and negatively affects quality of life and mortality. Evidence supports the use of integrative oncology (IO) practices to treat SD, but there is limited published data on the characteristics of SD and factors associated with SD in IO. We determined the prevalence, severity, and factors associated with SD.

\section{Methods}

Patients with cancer referred for initial outpatient IO consultation in 2017 were eligible. Patient demographics, clinical characteristics, and patient-reported outcomes [Edmonton Symptom Assessment Scale, (ESAS), Measure Yourself Concerns and Wellbeing (MYCaW), PROMIS-10] were retrospectively reviewed.

\section{Results}

1520 patients were included in the analysis. The majority (70\%) were women with breast cancer $(42 \%)$. $971(64 \%)$ patients reported significant SD with ESAS Sleep $\geq 4$, yet only $11 \%$ expressed poor sleep as their primary or secondary concern for the IO consultation. The median SD (IQR) was $5(3,7)$. ESAS scores for fatigue (adjusted OR 1.16; Cl 1.07-1.26, p<0.001), pain (adjusted OR 1.07; Cl 1.00-1.15, p< 0.05), hot flashes (adjusted OR 1.14; Cl 1.07-1.22, $\mathrm{p}<0.001$ ), well-being (adjusted OR 1.33; $\mathrm{Cl} 1.22-1.46, \mathrm{p}<0.001$ ), and psychological distress score (anxiety and depression) (adjusted OR 1.16; $\mathrm{Cl} 1.01-1.11, \mathrm{P}<0.01$ ) were independently associated with SD in multivariate analysis. Acupuncture was the most frequent intervention prescribed 175 (35\%). Other modalities included oncology massage (15\%), health psychology (5\%) and meditation (1\%).

\section{Conclusions}

Although $64 \%$ of patients seeking IO consultation reported clinically significant SD, only $11 \%$ were seeking integrative approaches for managing SD. ESAS fatigue, hot flashes, well-being, and psychological symptoms were significantly associated with SD.

\section{Introduction}

Sleep disturbance (SD) is common in cancer patients, with a prevalence of 23 to $61 \%$ compared to the general population (9-30\%). ${ }^{1-5}$ Prevalence of SD in cancer can be attributed to emotional distress, physical pain, discomfort, the effects of cancer treatments, and adverse medication effects. Poor sleep has an impact on the immune system and inflammatory processes and plays a role in the 
psychoneuroimmunology axis. ${ }^{6}$ A systematic review highlighted that SD led to increased systemic inflammation. ${ }^{7}$ Improved sleep not only leads to decreased emotional distress, but also attenuates proinflammatory and counter-regulatory cytokines and increases cell-mediated immunity suggesting the significant role of sleep in regulating key cancer biological processes. ${ }^{6,8}$ Pharmacological management of insomnia is often used in patients with severe sleep disturbances. However, sleep medications are associated with adverse effects. Multiple systematic reviews conclude that cognitive behavioral therapy is an effective non-pharmacological intervention for insomnia. ${ }^{9}$ Evidence suggests that other nonpharmacological therapies such as acupuncture, massage, exercise, music therapy, progressive muscle relaxation, meditation, yoga, and tai-chi also can help improve insomnia. ${ }^{10-17}$

Cancer patients frequently use complementary and integrative medicine (CIM) therapies with recent estimates as high as $69 \% .{ }^{18}$ Most CIM modalities such as yoga, tai-chi, meditation, and music therapy are safe to use for most patients. Herb and supplement use may have more risks than benefits. ${ }^{19}$ Although some herbs such as valerian root may help with $\mathrm{SD},{ }^{20}$ most patients use herbs and supplements without health care professional guidance increasing the chances of negative drug-herb interactions. ${ }^{21}$ To navigate the vast amount of information and to make an informed decision, patients often seek medical advice. IO programs are becoming more widely available in several cancer centers to address such needs and guide patients appropriately. ${ }^{22}$ The practice of integrative oncology/medicine seeks to optimize health, quality of life, and clinical outcomes utilizing mind and body practices, natural products and/or lifestyle modifications from different traditions alongside conventional cancer treatment. ${ }^{23}$ Therefore, SD can be treated using an integrative approach combining non-pharmacological and pharmacological therapies, or, ideally, non-pharmacological therapies alone.

SD is a common symptom in cancer patients seeking our 10 consultations. ${ }^{24}$ Patients attending the Integrative Medicine Center at The University of Texas MD Anderson Cancer Center are often referred to meditation, yoga, or tai chi group classes, physical therapy, acupuncture, and health psychology as a part of the treatment plan for SD after initial consultation. There is limited literature on the frequency and severity of sleep disturbances at the time of initial IO consultation, factors that are associated with SD, and 10 strategies used by patients with SD. This descriptive, retrospective study examined the frequency and severity of SD at the initial IO consultation and explored factors associated with SD by analyzing data from clinical records of patient's evaluated in our outpatient IO clinic. We also describe integrative therapies commonly used by patients who reported SD.

\section{Methods}

Data were extracted from patients seen for new consults at our 10 outpatient clinic at MD Anderson from January 1, 2017 to December 31, 2017. All patients presenting for a new patient consultation were asked to complete a series of assessments as part of the standard of care; only patients $\geq 18$ years of age and presenting for their initial IO consultation were eligible for the study. This study was approved by Institutional Review Board of UT MD Anderson Cancer Center, and waiver of consent was obtained. 


\section{Intervention (10 Consultation)}

Prior to the patient-provider (physician and/or advanced practice provider) consultation, a nurse administered the patient reported outcome (PRO) assessments. This comprehensive assessment of patient self-reported data is then entered into the medical record and made available to the physicians and advance practice providers immediately before the patient evaluation. During the 10 consultation, each patient is evaluated comprehensively in terms of their overall health, goals of care, and strategies to optimize their health. Referrals are then made to other IO services according to the individual's physical, mind-body, or social needs.

Assessment for patients with self-reported SD may include evaluation of factors contributing to SD such as medical and cancer history, symptom burden, review of cancer treatments, medications, and supplements. Then, an integrative care plan is developed for SD which may include review of sleep hygiene, suggestion for medical evaluation (e.g., sleep study), and review of integrative approaches such as acupuncture for symptom control or sleep, health psychology for cognitive behavioral therapyinsomnia, meditation, music therapy for psychological distress, yoga or tai-chi/qigong, or discussion of evidence-informed risks and benefits for herb/supplements or alternative treatments being pursued or considered by patients for SD or other reasons.

\section{Measures}

The patient demographics clinical characteristics and the following PRO assessments which are routinely collected as a part of the clinical care were retrospectively reviewed in all eligible patients from the electronic medical records. The PRO's included: Measure Yourself Concerns and Wellbeing (MYCaW), the Patient-Reported Outcomes Measurement Information System (PROMIS-10), and modified Edmonton Symptom Assessment Scale (ESAS).

\section{Measure Yourself Concerns and Wellbeing (MYCaW)}

Patients completed a modified version of the MYCaW questionnaire. ${ }^{25}$ Patients reported their top two concerns for their 10 encounter from a list of symptoms and concerns. The list includes sleep, integrative/holistic approach, herb/supplements, diet/nutrition, pain, overall health, and stress/anxiety, as well as an "other" category.

\section{Edmonton Symptom Assessment Scale (ESAS)}

Patient symptom burden was assessed using the modified ESAS. ${ }^{26}$ Patients are asked to report on 16 items: 10 core symptoms (pain, fatigue, nausea, depression, anxiety, drowsiness, loss of appetite, decreased sense of well-being, shortness of breath, and sleep) and an additional 6 items (spiritual distress, financial distress, numbness/tingling, hot flashes, dry mouth, and memory) -as experienced in the last 24 hours on a numeric scale of 0 to 10, with 10 being the worst. A change or difference of 1 on an individual item is viewed as a clinically significant difference in that symptom. ${ }^{27}$ Subscale scoring was as follows: global distress score (GDS, range: 0-90) sum of pain, fatigue, nausea, drowsiness, appetite, 
shortness of breath, anxiety, depression, and well-being scores; physical distress score (PHS, range: 0-60) sum of pain, fatigue, nausea, drowsiness, appetite, and shortness of breath; psychological distress score (PSS, range: 0-20) sum of anxiety and depression. ESAS sleep disturbance scores of 4 or above have good sensitivity and a reasonable specificity to screen for SD and is what was used in this study to define clinically significant SD. ${ }^{28}$

\section{Patient-Reported Outcome Measurement Information System (PROMIS-10 scores):}

PROMIS-10 scores intend to reflect the patient's own assessment of their QOL. The PROMIS- $10,{ }^{29}$ an assessment of global health, includes 10 self-report items that can be divided into mental health and physical health subscales. Responses are converted into T-score values, with T-score distributions standardized to the mean for the US population. Higher scores represent better global, mental, or physical health.

\section{Statistical Analyses}

The primary aim of this study was to determine the frequency and severity of SD in patients presenting for an 10 consultation. The secondary aim was to describe the factors that are associated with SD in cancer patients and the 10 treatments used. Descriptive statistics were used to describe the demographic and clinical characteristics of the patients. ESAS and PROMIS-10 scores were summarized with means, standard deviations, and ranges. We examined medical and demographic characteristics between those reporting clinically significant SD and those who did not using t-test for continuous characteristics and chi-squared test for categorical characteristics. We conducted univariate logistic regression analyses to examine independent factors associated with clinically significant SD. Variables significant in the univariate regressions were included in the logistic regression. A p-value of $\leq 0.05$ was considered statistically significant. All statistical analyses were performed using Stata/MP v16.0 (College Station, $\mathrm{TX})$.

\section{Results}

A total of 1566 patients were screened and 1520 patients were included in the analysis. The reasons for exclusion were: age below 18, no cancer diagnosis, and missing ESAS sleep. Table 1 represents the demographic and clinical characteristics of all patients, patients with ESAS sleep $>/=4$, and less than 4 . Seventy percent of the patients were women. Most common cancer diagnoses included breast (42\%) or gastrointestinal (14\%); close to one-third of the patients (32\%) had metastatic disease. The median (IQR) for SD was 5(3-7). Figure 1 shows the frequency and percentage for SD scores from the ESAS. Of 1520 patients, 1300 patients (86\%) reported ESAS sleep score as 2 or higher, 971 patients 4 or higher (64\%), and 447 patients 7 or higher (29\%). However, only 164 of 1520 patients (11\%) reported sleep as the primary or secondary concern on the MYCaW for seeking the 10 consultation. The primary concern listed for consultation included integrative approach and overall health $(316,21 \%)$, diet advice $(232,15 \%)$, pain $(221,14 \%)$, stress/anxiety, depression, relaxation (152,10\%), neuropathy $(144,10 \%)$, natural product 
information $(108,7 \%)$, fatigue $(78,5 \%)$ and others such as dry mouth, exercise, hot flashes, appetite loss, memory, nausea and spirituality. 
Table 1

Demographic and Clinical Differences of Patients with Sleep Disturbances in Patients Referred for an Ambulatory Integrative Medicine Consultation

\begin{tabular}{|c|c|c|c|c|}
\hline \multirow[t]{2}{*}{ Characteristic } & ESAS 0-10 & ESAS (SD) $<4^{1}$ & $\operatorname{ESAS}(S D) \geq 4^{1}$ & \multirow[t]{2}{*}{ P-value } \\
\hline & $N=1520$ & $N=549$ & $N=971$ & \\
\hline Age, Mean (SD) & $56.64(12.88)$ & $57.39(13.21)$ & $55.64(12.88)$ & 0.012 \\
\hline Gender, N (\%) & & & & 0.073 \\
\hline Female & $1067(70.2)$ & $370(67.4)$ & $697(71.78)$ & \\
\hline Male & $453(29.8)$ & $179(32.6)$ & $274(28.22)$ & \\
\hline BMI, N (\%) & & & & 0.102 \\
\hline$<25$ & $607(41.41)$ & $233(43.71)$ & $374(40.09)$ & \\
\hline $25-30$ & 449 (30.63) & $164(30.77)$ & 285 (30.55) & \\
\hline $30-35$ & $242(16.51)$ & $89(16.7)$ & $153(16.4)$ & \\
\hline$>35$ & 168 (11.46) & 47 (8.82) & $121(12.97)$ & \\
\hline Cancer, N (\%) & & & & 0.2 \\
\hline Breast & $638(42.08)$ & $223(40.77)$ & $415(42.83)$ & \\
\hline Central Nervous System & $42(2.77)$ & $19(3.47)$ & $23(2.37)$ & \\
\hline Endocrine & $40(2.64)$ & $12(2.19)$ & $28(2.89)$ & \\
\hline Gastrointestinal & $206(13.59)$ & $82(14.99)$ & $124(12.8)$ & \\
\hline Genitourinary & $151(9.96)$ & $61(11.15)$ & $90(9.29)$ & \\
\hline Gynecologic & $77(5.08)$ & $27(4.94)$ & $50(5.16)$ & \\
\hline Head/neck & $110(7.26)$ & $44(8.04)$ & $66(6.81)$ & \\
\hline Heme & $113(7.45)$ & $30(5.48)$ & $83(8.57)$ & \\
\hline Others & $13(0.86)$ & $5(0.91)$ & $8(0.83)$ & \\
\hline Sarcoma & $3(22.11)$ & $16(2.93)$ & $16(1.65)$ & \\
\hline Skin & $31(2.04)$ & $9(1.65)$ & $22(2.27)$ & \\
\hline Thoracic & $63(4.16)$ & $19(3.47)$ & $44(4.54)$ & \\
\hline
\end{tabular}

${ }^{1}$ ESAS (SD) $<$ or $\geq 4$ = Edmonton Symptom Assessment Scale - sleep disturbance score less than 4 or equal to or greater than 4

*Data not available for all patients 


\begin{tabular}{|c|c|c|c|c|}
\hline \multirow[t]{2}{*}{ Characteristic } & ESAS 0-10 & ESAS (SD) $<4^{1}$ & ESAS $(S D) \geq 4^{1}$ & \multirow[t]{2}{*}{ P-value } \\
\hline & $N=1520$ & $N=549$ & $N=971$ & \\
\hline \multicolumn{4}{|l|}{ Metastasis, N (\%) } & 0.36 \\
\hline No & $1021(68.39)$ & $360(66.91)$ & $661(69.21)$ & \\
\hline Yes & $472(31.61)$ & $178(33.09)$ & $294(30.79)$ & \\
\hline \multicolumn{4}{|l|}{ Opioid Use*, N (\%) } & 0.003 \\
\hline No & $521(58.21)$ & $205(64.87)$ & $316(54.58)$ & \\
\hline Yes & $374(41.79)$ & $111(35.13)$ & $263(45.42)$ & \\
\hline \multicolumn{4}{|l|}{ Steroid Use*, N (\%) } & 0.55 \\
\hline No & $7(88)$ & $281(88.92)$ & $507(87.56)$ & \\
\hline Yes & $107(11.96)$ & 35 (11.08) & $72(12.44)$ & \\
\hline \multicolumn{4}{|l|}{ Stimulant use*, N (\%) } & 0.175 \\
\hline No & $862(96.31)$ & $308(97.47)$ & $554(95.68)$ & \\
\hline Yes & $33(3.69)$ & $8(2.53)$ & $25(4.32)$ & \\
\hline \multicolumn{4}{|l|}{ Benzodiazepine use*, N (\%) } & 0.001 \\
\hline No & $748(83.58)$ & $281(88.92)$ & $467(80.66)$ & \\
\hline yes & $147(16.42)$ & 35 (11.08) & $112(19.34)$ & \\
\hline \multicolumn{5}{|c|}{$\begin{array}{l}{ }^{1} \text { ESAS }(S D)<\text { or } \geq 4=\text { Edmonton Symptom Assessment Scale - sleep disturbance score less than } 4 \text { or } \\
\text { equal to or greater than } 4\end{array}$} \\
\hline \multicolumn{5}{|c|}{${ }^{*}$ Data not available for all patients } \\
\hline
\end{tabular}

Comparing patients reporting clinically significant SD (ESAS sleep $\geq 4$ ) to those who did not revealed that patients with SD tended to be younger than those without $S D(S D=55.6$ vs. No $S D=57.9$ years, $p=0.012$ ) (Table 1). Opioid use was also significantly higher in the cohort with clinically significant SD compared to those without clinically significant SD (45.4 vs. $35.1, p=0.003)$. There were no other demographic or medical characteristic differences between those with and without clinically meaningful SD. Table 2 shows that the symptom burden was higher in the group with ESAS sleep $\geq 4$. 
Table 2

Symptom Burden of Patients with Sleep Disturbance

\begin{tabular}{|c|c|c|c|}
\hline ESAS Variable & ESAS 0-10 & ESAS (SD) < $4^{1}$ & ESAS $(S D) \geq 4^{1}$ \\
\hline & $N=1520$ & $N=549$ & $N=971$ \\
\hline & Median (IQR) & Median (IQR) & Median (IQR) \\
\hline Anxiety & $3(1,5)$ & $1(0,3)$ & $3.5(1,6)$ \\
\hline Depression & $1(0,4)$ & $0(0,2)$ & $2(0,5)$ \\
\hline Drowsiness & $2(0,5)$ & $1(0,3)$ & $3(1,5)$ \\
\hline Fatigue & $5(2,7)$ & $3(1,5)$ & $5(3,7)$ \\
\hline Memory & $3(2,5)$ & $2(1,4)$ & $4(2,6)$ \\
\hline Nausea & $0(0,2)$ & $0(0,0)$ & $0(0,3)$ \\
\hline Numbness \&Tingling & $0(0,2)$ & $1(0,3)$ & $2(0,6)$ \\
\hline Hot Flashes & $0(0,4)$ & $0(0,2)$ & $1(0,5)$ \\
\hline Pain & $3(1,6)$ & $2(0,4)$ & $4(1,6)$ \\
\hline Well-being & $4(2,6)$ & $2(1,4)$ & $5(3,6)$ \\
\hline Shortness of Breath & $0(0,2)$ & $1(0,1)$ & $1(0,3)$ \\
\hline Spiritual Pain & $0(0,2)$ & $0(0,1)$ & $0(0,3)$ \\
\hline Appetite & $3(0,5)$ & $1(0,3)$ & $4(1,5)$ \\
\hline Financial distress & $0(0,2)$ & $1(0,3)$ & $3(0,5)$ \\
\hline Dry mouth & $1(0,4)$ & $3(1,5)$ & $5(3,7)$ \\
\hline $\mathrm{PHS}^{\mathrm{a}}$ & $15(9,24)$ & $10(5,16)$ & $19(12,26)$ \\
\hline PSS $^{b}$ & $4(1,8)$ & $2(0,5)$ & $6(2,10)$ \\
\hline GDS $^{\mathrm{C}}$ & $24(14,36)$ & $14(8,24)$ & $29(21,41)$ \\
\hline PROMIS PH ${ }^{d}$ & $13(11,15)$ & $15(13,17)$ & $12(10,15)$ \\
\hline PROMIS MH & $13(11,15)$ & $14(12,16)$ & $12(10,14)$ \\
\hline
\end{tabular}


aPHS equals the sum of pain, fatigue, nausea, drowsiness, appetite, and shortness of breath scores (total $0-60$ ); ${ }^{b}$ PSS equals the sum of depression and anxiety scores (total $0-20$ ); ${ }^{c}$ GDS equals the sum of pain, fatigue, nausea, depression, anxiety, drowsiness, appetite, sense of well-being, and shortness of breath scores (total 0-90).

PROMIS10 scores includes a physical health (PROMIS PH ${ }^{d}$ ) scale (4-20) and mental health (PROMIS $\mathrm{MH}^{\mathrm{e}}$ ) subscale (4-20). Higher scores represent better mental, physical or global health.

Abbreviations: ESAS, Edmonton Symptom Assessment Scale; PHS, physical distress score; PSS, psychological distress score; GDS, global distress score.

Table 3 shows univariate logistic regression analyses of factors associated with clinically significant SD, revealing that all ESAS symptoms, PROMIS, age, BMI, and opioid use were associated with SD.

Multivariate analysis of the significant variables revealed ESAS fatigue (adjusted OR 1.16; CI 1.07-1.26, $\mathrm{p}<0.01$ ), ESAS pain (adjusted OR 1.07; Cl 1.00-1.15, $\mathrm{p}<0.05$ ), ESAS hot flashes (adjusted OR 1.14; $\mathrm{Cl}$ 1.07-1.22, $\mathrm{p}<0.001$ ), well-being (adjusted OR 1.33; Cl 1.22-1.46, $\mathrm{p}<0.001$ ), and PSS (Psychological distress - the sum of ESAS anxiety and depression) (adjusted OR 1.16; Cl 1.01-1.11, $\mathrm{P}<0.01$ ) remained as factors independently associated with clinically significant SD. Age, BMI, opioid use, symptoms such as nausea, numbness and tingling, shortness of breath were not significant in multivariate model (NB: PHS, GDS, PROMIS PH and PROMIS MH were not included in the final analysis as they are a combination of other variables or overlap significantly). 
Table 3

Univariate and Multivariate Models for Factors Associated With Sleep Disturbances

Covariates

Odds Ratio
$(95 \% \mathrm{Cl})$

Age

$0.99(0.98-$

1.00)

Gender

Women vs men

$0.81(0.65-$

1.02)

\section{Body mass index}

Overweight 25-29.9 vs Normal

Weight

Obese $30-35$ vs Normal Weight

Moderate risk obesity $>35$ vs

Normal Weight
$1.08(0.84-$

1.39)

$1.07(0.79-$

1.46)

$1.60(1.10-$

2.33)
Multivariate p-
value
Adjusted Odds Ratio (95\%
Cl)

0.9

$1.01)$

NA

NA

$.00(0.99-$

\section{Metastasis}

Metastatic vs Non-Metastatic

$0.90(0.72-$

1.13)

Opioid use

1.54 (1.16-

2.04)

0.537

NA

NA

0.073

$1.14(0.74-$

1.75)

0.663

\section{Steroid use}

Stimulant use
$1.74(0.77-$
3.90)

0.013

$1.08(0.60-$

0.794

1.93)

0.359 NA NA

$\left.0.003 \quad \frac{0.921}{1.34}\right)$
$\left(\begin{array}{ll}0.63- & 0.67\end{array}\right.$

$0.549 \mathrm{NA}$

NA

NA NA

\section{ESAS}

Anxiety

$1.29(1.24-$

1.35)

$<001 \quad$ NA

NA

${ }^{\text {aPSS }}$ is the sum of depression and anxiety scores (total 0-20)

bPHS equals the sum of pain, fatigue, nausea, drowsiness, appetite, and shortness of breath scores (total 0-60)

'GDS equals the sum of pain, fatigue, nausea, depression, anxiety, drowsiness, appetite, sense of wellbeing, and shortness of breath scores (total 0-90). PROMIS10 scores includes a physical health $\left(P R O M I S P^{d}\right)$ scale (4-20) and mental health (PROMIS MHe) subscale (4-20). Higher scores represent better mental, physical or global health.

Abbreviations: ESAS, Edmonton Symptom Assessment Scale; PSS, psychological distress score; GDS, global distress score; PROMIS-PH - physical health; PROMIS-MH - mental health. 


\section{Odds Ratio $(95 \% \mathrm{Cl})$ \\ p- $\quad$ Adjusted Odds Ratio (95\% \\ value $\mathrm{Cl}$ )

Depression

\begin{tabular}{|c|c|c|c|c|}
\hline \multirow[b]{2}{*}{ Drowsiness } & $\begin{array}{l}1.34(1.27- \\
1.41)\end{array}$ & $\begin{array}{l}< \\
0.001\end{array}$ & & \\
\hline & $\begin{array}{l}1.31(1.25- \\
1.38)\end{array}$ & $<0.001$ & & \\
\hline Fatigue & $\begin{array}{l}1.33(1.27- \\
1.39)\end{array}$ & $\begin{array}{l}<.001 \\
0.0\end{array}$ & $\begin{array}{l}1.16(1.07- \\
1.26)\end{array}$ & 0.01 \\
\hline Nausea & $\begin{array}{l}1.21(1.14- \\
1.28)\end{array}$ & $<.001$ & $\begin{array}{l}0.97(0.89- \\
1.07)\end{array}$ & 0.59 \\
\hline Numbness \& Tingling & $\begin{array}{l}1.13(1.09- \\
1.17)\end{array}$ & $\begin{array}{l}<.001 \\
0.00\end{array}$ & $\begin{array}{l}1.03(0.97- \\
1.10)\end{array}$ & 0.29 \\
\hline Hot Flashes & $\begin{array}{l}1.22(1.17- \\
1.27)\end{array}$ & $\begin{array}{l}<.001 \\
0\end{array}$ & $\begin{array}{l}1.14(1.07- \\
1.22)\end{array}$ & 0.01 \\
\hline Pain & $\begin{array}{l}1.23(1.18- \\
1.28)\end{array}$ & $\begin{array}{l}<.001 \\
0.00\end{array}$ & $\begin{array}{l}1.07(1.00- \\
1.15)\end{array}$ & 0.05 \\
\hline
\end{tabular}

${ }^{\text {aPSS }}$ is the sum of depression and anxiety scores (total 0-20)

${ }^{b}$ PHS equals the sum of pain, fatigue, nausea, drowsiness, appetite, and shortness of breath scores (total 0-60)

'GDS equals the sum of pain, fatigue, nausea, depression, anxiety, drowsiness, appetite, sense of wellbeing, and shortness of breath scores (total 0-90). PROMIS10 scores includes a physical health (PROMIS $\mathrm{PH}^{\mathrm{d}}$ ) scale (4-20) and mental health (PROMIS MH ${ }^{\mathrm{e}}$ ) subscale (4-20). Higher scores represent better mental, physical or global health. Abbreviations: ESAS, Edmonton Symptom Assessment Scale; PSS, psychological distress score; GDS, global distress score; PROMIS-PH - physical health; PROMIS-MH - mental health. 


\begin{tabular}{|c|c|c|c|c|c|}
\hline \multirow{3}{*}{$\begin{array}{l}\text { Covariates } \\
\text { Well-being }\end{array}$} & \multicolumn{2}{|l|}{ Univariate } & \multicolumn{3}{|l|}{ Multivariate } \\
\hline & $\begin{array}{l}\text { Odds Ratio } \\
\text { (95\% Cl) }\end{array}$ & $\begin{array}{l}\mathrm{p}- \\
\text { value }\end{array}$ & $\begin{array}{l}\text { Adjusted Odds } \\
\text { Cl) }\end{array}$ & Ratio (95\% & $\begin{array}{l}\text { p- } \\
\text { value }\end{array}$ \\
\hline & $\begin{array}{l}1.47(1.39- \\
1.55)\end{array}$ & $\begin{array}{l}<.001 \\
0.00\end{array}$ & $\begin{array}{l}1.33(1.12- \\
1.46)\end{array}$ & 0.01 & \\
\hline Shortness of Breath & $\begin{array}{l}1.22(1.15- \\
1.29)\end{array}$ & $<.001$ & $\begin{array}{l}0.96(0.87- \\
1.06)\end{array}$ & 0.41 & \\
\hline Spiritual Pain & $\begin{array}{l}1.34(1.25- \\
1.43)\end{array}$ & $<0.001$ & $\begin{array}{l}1.10(0.97- \\
1.23)\end{array}$ & 0.12 & \\
\hline $\mathrm{PSS}^{\mathrm{a}}$ & $\begin{array}{l}1.18(1.1- \\
1.21)\end{array}$ & $\begin{array}{l}< \\
0.001\end{array}$ & $\begin{array}{l}1.06(1.01- \\
1.11)\end{array}$ & 0.01 & \\
\hline $\mathrm{PHS}^{\mathrm{b}}$ & $1.10(1.0-1.11)$ & $<.001$ & NA & NA & \\
\hline $\mathrm{GDS}^{\mathrm{c}}$ & $\begin{array}{l}1.08(1.07- \\
1.09)\end{array}$ & $\begin{array}{l}< \\
0.001\end{array}$ & NA & NA & \\
\hline PROMIS-PH & $\begin{array}{l}0.80(0.77- \\
0.83)\end{array}$ & $<.001$ & NA & NA & \\
\hline PROMIS-MH & $\begin{array}{l}0.79(0.76- \\
0.82)\end{array}$ & $<.001$ & & & \\
\hline
\end{tabular}

aPSS is the sum of depression and anxiety scores (total 0-20)

${ }^{b}$ PHS equals the sum of pain, fatigue, nausea, drowsiness, appetite, and shortness of breath scores (total 0-60)

${ }^{c}$ GDS equals the sum of pain, fatigue, nausea, depression, anxiety, drowsiness, appetite, sense of wellbeing, and shortness of breath scores (total 0-90). PROMIS10 scores includes a physical health (PROMIS PH ${ }^{d}$ ) scale (4-20) and mental health (PROMIS MHe) subscale (4-20). Higher scores represent better mental, physical or global health.

Abbreviations: ESAS, Edmonton Symptom Assessment Scale; PSS, psychological distress score; GDS, global distress score; PROMIS-PH - physical health; PROMIS-MH - mental health.

Of 971 patients with ESAS SD $\geq 4,495$ patients used IO services on follow up. As a part of their IO treatment plan, integrative clinical services utilized by patients reporting SD included acupuncture 35\% (n = 175), oncology massage $15 \%((n=75)$, health psychology $5 \%(n=24)$ and meditation $1 \%(n=6)$.

\section{Discussion}

While the majority ( $86 \%$ ) of patients seen in our IO clinic reported SD, only $11 \%$ of patients reported SD as a primary or secondary concern for seeking the 10 consultation. This could be due to a lack of awareness of integrative treatment options for SD, not prioritizing SD as a health concern, or that other symptoms or 
reasons were a priority over SD. Research by Degnon et al. found that patients worst symptoms on a numeric scale were not always consistent with what was causing them the most distress and what they prioritized for symptom management. Garland et. al, also reported that cancer patients were reluctant to use sleep medications, but felt that they were the only available choice for treating SD. ${ }^{30}$ Evaluating SD and sleep management warrants more discussion and support.

Our study found that clinically significant SD (ESAS $\geq 4$ ) was correlated with other symptoms of physical or emotional distress. However, the cause-and-effect relationship cannot be determined with the current data as to whether SD aggravates some of the symptoms or if certain symptoms lead to SD. It is likely a bidirectional relationship. These findings were similar to other studies where ESAS symptoms were intercorrelated, especially sleep with anxiety and depression. ${ }^{31}$ Our study found that opioid use, obesity, physical health symptoms such as fatigue, hot flashes, pain, psychological symptoms such as anxiety and depression were associated with SD in a multivariate model. This is consistent with other studies showing that anxiety, depression, fatigue, pain, and performance status are strong predictors of SD. ${ }^{32}$ Studies have shown that insomnia often co-occurs with pain, fatigue, anxiety, and depression as a symptom cluster. ${ }^{33}$ These symptom clusters may negatively impact the quality of life of cancer patients. ${ }^{34}$ The relationship between opioid use and sleep disorders ${ }^{35}$ and obesity and sleep disorders 36,37 has been well recognized and was noted in our findings as well. Therefore, for patients receiving 10 with SD, integrative therapies such as acupuncture, massage, health psychology counseling, and meditation were common interventions prescribed by $\mathrm{IO}$ clinicians. A systematic review showed acupuncture to be superior to sham acupuncture for managing cancer related insomnia. ${ }^{10}$ However, the number of patients using acupuncture and oncology massage would have been higher if the service were more widely covered by insurance. Underutilization due to cost was shown in a cross-sectional survey of cancer patients on acupuncture use for pain. ${ }^{38}$ Yoga and Tai chi were also recommended, as well as sleep hygiene, but the yoga/meditation service use was limited secondary to cost and availability as well. We noted that CBT-I, although considered as the gold standard for management of insomnia, ${ }^{39}$ was not commonly used in our practice. This could be related to the availability and focus of integrative/health psychologists versus patient related factors such as stigma beliefs about therapy. With CBT-I requiring multiple in-person sessions, other competing interventions as part of cancer care may have made this a less feasible choice for management of SD.

There are several limitations to this study. We used ESAS score for sleep to measure SD in our patients. This scale is not designed specifically to assess clinically meaningful sleep disturbances in cancer patients. It is also a measure of SD in the past 24 hours and might not reflect a true assessment of SD in patients. However, due to prior data showing a good correlation of ESAS sleep $\geq 4$ with clinically significant SD, and the retrospective nature of the study, we decided to use this as a primary measure. Also, the study is cross-sectional in nature, and does not report if patients had any improvement in SD after 10 approaches. Further studies are needed. Not all IO interventions recommended to patients as part of their IO were specifically recommended for the management of SD. A prospective study design will help measure the impact of multimodal intervention in real world IO practice. Lastly, our patient 
population was predominantly women with breast cancer adding to the limitation of generalizability of the study results to other cancer-types and men. Despite these limitations, our data is informative to clinicians regarding the importance of screening for SD using patient reported outcomes, although patients may not prioritize engaging in a discussion about the management of SD. Targeting modifiable risk factors such as hot flashes with 10 modalities (e.g., acupuncture) may improve SD at the same time as treating hot flashes. Therefore, our preliminary data on 10 interventions used in the management of SD could provide insight into and inform the development of a multi-modal approach incorporating pharmacological and integrative therapies. Also, factors associated with use of IM therapies need to be explored in future studies.

\section{Conclusions And Future Directions}

We found that SD is common in cancer patients presenting for 10 consultation. Despite the availability of non-pharmacological interventions, only a small proportion of patients identified SD as a primary or secondary concern when seeking an IO consultation. ESAS fatigue, hot flashes, well-being, and psychological symptoms were significantly associated with SD. The IO clinical model, including routine comprehensive symptom assessment and multi-disciplinary management, can successfully engage patients in a discussion on addressing SD in the context of other health areas. Greater dissemination of evidence-based information on integrative approaches for managing insomnia would help patients develop a more comprehensive approach to their symptom management needs, using the best combination of pharmacologic and non-pharmacologic options. Future research should focus on multimodal interventions for managing insomnia and associated symptoms in cancer patients.

\section{Declarations}

Acknowledgements: We acknowledge Bryan Fellman for his statistical advise, Patrick King and Telma Gomez for their help with data collection.

Funding: None

Conflicts of interest/Competing interests: None

Availability of data and material: Available in MD Anderson database

Code availability: N/A

Authors' contributions: Santhosshi Narayanan and Akhila Reddy are first authors who designed and directed the project under the guidance of Dr. Yennuramalingam and Dr. Bruera and involved in all stages of the project including manuscript writing. Drs. Cohen and Yennuramalingam directed the statistical analysis plan and direct the writing as senior authors. Dr. Gabriel Lopez was involved in data gathering and manuscript writing. Dr. Wenli Liu and Ms. Sarah Ali helped were involved in manuscript writing.

Ethics approval: IRB approval number PA 18-0885 
Consent to participate: It is a retrospective study which is IRB approved

Consent for publication: It is a retrospective study which is IRB approved

Conflict of interests: None

I have full control of all primary data and if you agree to allow the journal to review their data if requested.

\section{References}

1. Palesh OG, Roscoe JA, Mustian KM et al (2010) Prevalence, demographics, and psychological associations of sleep disruption in patients with cancer: University of Rochester Cancer CenterCommunity Clinical Oncology Program. Journal of clinical oncology: official journal of the American Society of Clinical Oncology 28(2):292-298. doi:10.1200/jco.2009.22.5011

2. Savard J, Simard S, Blanchet J, Ivers H, Morin CM (2001) Prevalence, clinical characteristics, and risk factors for insomnia in the context of breast cancer. Sleep 24(5):583-590. doi:10.1093/sleep/24.5.583

3. Weyerer S, Dilling H (1991) Prevalence and treatment of insomnia in the community: results from the Upper Bavarian Field Study. Sleep 14(5):392-398. https://www.ncbi.nlm.nih.gov/pubmed/1759091

4. Hoang HTX, Molassiotis A, Chan CW, Nguyen TH, Liep Nguyen V (2020) New-onset insomnia among cancer patients undergoing chemotherapy: prevalence, risk factors, and its correlation with other symptoms. Sleep breathing = Schlaf Atmung 24(1):241-251. doi:10.1007/s11325-019-01839-x

5. Garland SN, Rowe H, Repa LM, Fowler K, Zhou ES, Grandner MA (2018) A decade's difference: 10year change in insomnia symptom prevalence in Canada depends on sociodemographics and health status. Sleep Health 4(2):160-165. doi:10.1200/jco.2012.47.7265

6. Irwin MR (2015) Why sleep is important for health: a psychoneuroimmunology perspective. Annu Rev Psychol 66:143-172. doi:10.1146/annurev-psych-010213-115205

7. Irwin MR, Olmstead R, Carroll JE. Sleep Disturbance (2016) Sleep Duration, and Inflammation: A Systematic Review and Meta-Analysis of Cohort Studies and Experimental Sleep Deprivation. Biol Psychiatry 80(1):40-52. doi:10.1016/j.biopsych.2015.05.014

8. Tucker JA, Osann K, Hsieh S et al (2021) Longitudinal Changes in Sleep: Associations with Shifts in Circulating Cytokines and Emotional Distress in a Cancer Survivor Population. Int J Behav Med 28(1):140-150. doi:10.1007/s12529-020-09950-0

9. Rios P, Cardoso R, Morra D et al (2019) Comparative effectiveness and safety of pharmacological and non-pharmacological interventions for insomnia: an overview of reviews. Systematic reviews 8(1):281. doi:10.1186/s13643-019-1163-9

10. Choi TY, Kim JI, Lim HJ, Lee MS (2017) Acupuncture for Managing Cancer-Related Insomnia: A Systematic Review of Randomized Clinical Trials. Integr Cancer Ther 16(2):135-146.

doi:10.1177/1534735416664172

Page 16/20 
11. Mercier J, Ivers H, Savard J. A non-inferiority randomized controlled trial comparing a home-based aerobic exercise program to a self-administered cognitive-behavioral therapy for insomnia in cancer patients. Sleep 2018;41(10). doi:10.1093/sleep/zsy149

12. Akgun Sahin Z, Dayapoglu N (2015) Effect of progressive relaxation exercises on fatigue and sleep quality in patients with chronic obstructive lung disease (COPD). Complement Ther Clin Pract 21(4):277-281. doi:10.1016/j.ctcp.2015.10.002

13. Blanaru $M, B$ Bloch $B$, Vadas $L$ et al (2012) The effects of music relaxation and muscle relaxation techniques on sleep quality and emotional measures among individuals with posttraumatic stress disorder. Ment Illn 4(2):e13. doi:10.4081/mi.2012.e13

14. Rusch HL, Rosario M, Levison LM et al (2019) The effect of mindfulness meditation on sleep quality: a systematic review and meta-analysis of randomized controlled trials. Annals of the New York Academy of Sciences 1445(1):5-16. doi:10.1111/nyas.13996

15. Mustian KM (2013) Yoga as Treatment for Insomnia Among Cancer Patients and Survivors: A Systematic Review. European medical journal Oncology 1:106-115. https://www.ncbi.nlm.nih.gov/pmc/articles/PMC4204627/pdf/nihms544176.pdf

16. Siu PM, Yu AP, Tam BT et al (2021) Effects of Tai Chi or Exercise on Sleep in Older Adults With Insomnia: A Randomized Clinical Trial. JAMA Netw Open 4(2):e2037199.

doi:10.1001/jamanetworkopen.2020.37199

17. Kashani F, Kashani $P$ (2014) The effect of massage therapy on the quality of sleep in breast cancer patients. Iranian journal of nursing midwifery research 19(2):113-118

18. Navo MA, Phan J, Vaughan C et al (2004) An assessment of the utilization of complementary and alternative medication in women with gynecologic or breast malignancies. Journal of clinical oncology: official journal of the American Society of Clinical Oncology 22(4):671-677. doi:10.1200/jco.2004.04.162

19. White CM (2020) Dietary Supplements Pose Real Dangers to Patients. Ann Pharmacother 54(8):815819. doi:10.1177/1060028019900504

20. Shinjyo N, Waddell G, Green J (2020) Valerian Root in Treating Sleep Problems and Associated Disorders-A Systematic Review and Meta-Analysis. J Evid Based Integr Med 25:2515690X20967323-22515690X20967323. doi:10.1177/2515690X20967323

21. Richardson MA, Sanders T, Palmer JL, Greisinger A, Singletary SE (2000) Complementary/alternative medicine use in a comprehensive cancer center and the implications for oncology. Journal of clinical oncology: official journal of the American Society of Clinical Oncology 18(13):2505-2514. doi:10.1200/JC0.2000.18.13.2505

22. Brauer JA, El Sehamy A, Metz JM, Mao JJ (2010) Complementary and alternative medicine and supportive care at leading cancer centers: a systematic analysis of websites. J Altern Complement Med 16(2):183-186. doi:10.1089/acm.2009.0354

23. Witt CM, Balneaves LG, Cardoso MJ et al. A Comprehensive Definition for Integrative Oncology. Journal of the National Cancer Institute Monographs 2017;2017(52). 
doi:10.1093/jncimonographs/lgx012

24. Lopez G, McQuade J, Cohen L et al (2017) Integrative Oncology Physician Consultations at a Comprehensive Cancer Center: Analysis of Demographic, Clinical and Patient Reported Outcomes. Journal of Cancer 8(3):395-402. doi:10.7150/jca.17506

25. Paterson C, Thomas K, Manasse A, Cooke H, Peace G (2007) Measure Yourself Concerns and Wellbeing (MYCaW): an individualised questionnaire for evaluating outcome in cancer support care that includes complementary therapies. Complement Ther Med 15(1):38-45. doi:10.1016/j.ctim.2006.03.006

26. Bruera E, Kuehn N, Miller MJ, Selmser P, Macmillan K. The Edmonton Symptom Assessment System (ESAS): a simple method for the assessment of palliative care patients. J Palliat Care. 1991;7(2):69. Retrieved from https://www.ncbi.nlm.nih.gov/pubmed/1714502

27. Hui D, Shamieh O, Paiva CE et al (2015) Minimal clinically important differences in the Edmonton Symptom Assessment Scale in cancer patients: A prospective, multicenter study. Cancer 121(17):3027-3035. doi:10.1002/cncr.29437

28. Yennurajalingam S, Balachandran D, Pedraza Cardozo SL et al (2017) Patient-reported sleep disturbance in advanced cancer: frequency, predictors and screening performance of the Edmonton Symptom Assessment System sleep item. BMJ Support Palliat Care 7(3):274-280. doi:10.1136/bmjspcare-2015-000847

29. Hays RD, Bjorner JB, Revicki DA, Spritzer KL, Cella D (2009) Development of physical and mental health summary scores from the patient-reported outcomes measurement information system (PROMIS) global items. Qual Life Res 18(7):873-880. doi:10.1007/s11136-009-9496-9

30. Garland SN, Carlson LE, Stephens AJ, Antle MC, Samuels C, Campbell TS (2014) Mindfulness-based stress reduction compared with cognitive behavioral therapy for the treatment of insomnia comorbid with cancer: a randomized, partially blinded, noninferiority trial. Journal of clinical oncology: official journal of the American Society of Clinical Oncology 32(5):449-457. doi:10.1200/jco.2012.47.7265

31. Yennurajalingam S, Tayjasanant S, Balachandran D et al (2016) Association between Daytime Activity, Fatigue, Sleep, Anxiety, Depression, and Symptom Burden in Advanced Cancer Patients: A Preliminary Report. J Palliat Med 19(8):849-856. doi:10.1089/.jpm.2015.0276

32. Jeon MS, Dhillon HM, Koh ES et al (2021) Exploring sleep disturbance among adults with primary or secondary malignant brain tumors and their caregivers. Neurooncol Pract 8(1):48-59. doi:10.1093/nop/npaa057

33. Fiorentino L, Rissling M, Liu L, Ancoli-Israel S (2011) The Symptom Cluster of Sleep, Fatigue and Depressive Symptoms in Breast Cancer Patients: Severity of the Problem and Treatment Options. Drug Discov Today Dis Models 8(4):167-173. doi:10.1016/j.ddmod.2011.05.001

34. Cheng KK, Yeung RM (2013) Impact of mood disturbance, sleep disturbance, fatigue and pain among patients receiving cancer therapy. European journal of cancer care 22(1):70-78. doi:10.1111/j.13652354.2012.01372.x 
35. Rosen IM, Aurora RN, Kirsch DB et al (2019) Chronic Opioid Therapy and Sleep: An American Academy of Sleep Medicine Position Statement. Journal of Clinical Sleep Medicine 15(11):16711673. doi:10.5664/jcsm. 8062

36. Parvaneh K, Poh BK, Hajifaraji M, Ismail MN (2014) Sleep deprivation is related to obesity and low intake of energy and carbohydrates among working Iranian adults: a cross sectional study. Asia Pac J Clin Nutr 23(1):84-90. doi:10.6133/apjen.2014.23.1.02

37. Alfano CM, Lichstein KL, Vander Wal GS et al (2011) Sleep duration change across breast cancer survivorship: associations with symptoms and health-related quality of life. Breast Cancer Res Treat 130(1):243-254. doi:10.1007/s10549-011-1530-2

38. Liou KT, Hung TKW, Meghani SH et al (2019) What if Acupuncture Were Covered by Insurance for Pain Management? A Cross-Sectional Study of Cancer Patients at One Academic Center and 11 Community Hospitals. Pain Med. doi:10.1093/pm/pnz087

39. Qaseem A, Kansagara D, Forciea MA, Cooke M, Denberg TD (2016) Management of Chronic Insomnia Disorder in Adults: A Clinical Practice Guideline From the American College of Physicians. Ann Intern Med 165(2):125-133. doi:10.7326/m15-2175

\section{Figures}




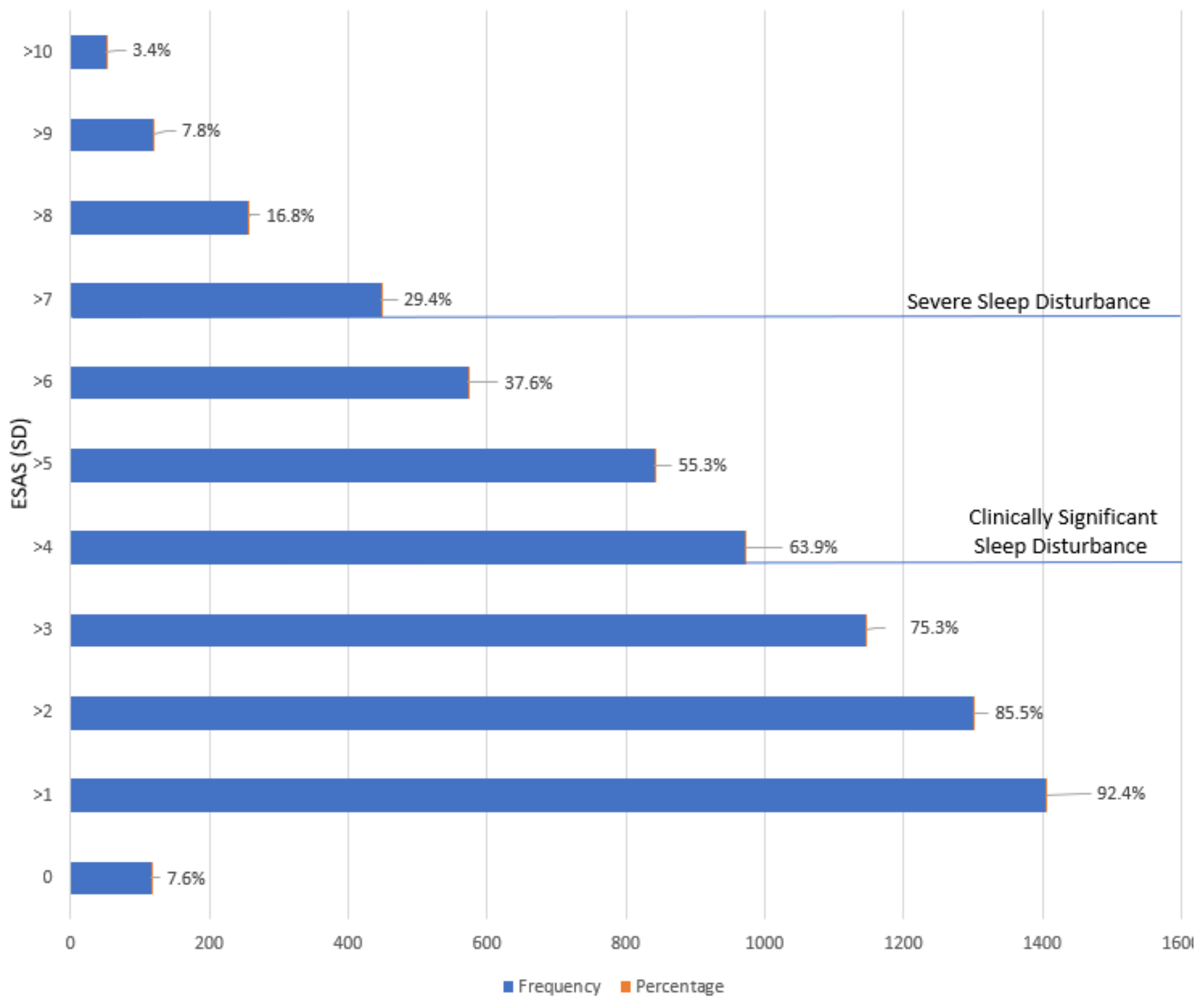

Figure 1

Frequency and Severity of Sleep Disturbances in Cancer Patients Referred to Integrative Oncology Abbreviations: ESAS, Edmonton Symptom Assessment Scale; SD, Sleep Disturbance 